\title{
ARQUEOLOGIA MODERNA DA MODERNIDADE
}

\author{
Manuel Afonso Costa* \\ manafcost@sapo.pt
}

RESUMO $A$ emergência da "Modernidade» está associada a um conjunto de categorias novas, quer do ponto de vista histórico, quer do ponto de vista sociológico, mas sobretudo do ponto de vista ético, moral e jurídico. Ao longo deste texto mostram-se alguns momentos onde algumas destas categorias começam a fazer o seu caminho, ainda que de uma forma incipiente e hesitante.

Palavras-chave Autonomia, Intuicionismo Moral, Secularização

ABSTRACT The emergence of "Modernity" is associated with a set of new categories, both of a historical perspective, or a sociological point of view, but especially ethical, moral and legal. Throughout this text we show a few moments where some of these ideas are beginning to make its way, albeit in an incipient and hesitant form.

Keywords Autonomy, Moral Intuitionism, Secularization

\section{Introdução}

Quando se passa em revista o balbuciar das ideias ético-morais e jurídicas da modernidade percebe-se que em nenhuma circunstância se encontra um pensamento totalmente moderno despojado de elementos arcaicos, relevem

* Doutor pela Faculdade de Ciências Sociais e Humanas (FCSH) da Universidade Nova de Lisboa (UNL) Departamento de Filosofia, em História das Ideias e Teoria dos Paradigmas. Artigo recebido em 7/2/2011 e aprovado em 26/4/2011. 
eles do teleologismo clássico e medieval ou, em contrapartida, de orientações de pensamento inovadoras mas ainda presas a fundamentações metafísicoreligiosas constitutivamente heterónomas. Eu teria tido uma grande desilusão se esperasse encontrar um pensamento à nossa medida, espectadores que somos agora de uma realidade que tornou os balbucios setecentistas, ultrapassados, o que tornaria as suas hesitações incompreensíveis e as suas ousadias muito frustres. Se não se for para esses textos com expectativas exageradas e insensatas, poder-se-á perceber melhor o alcance de tão profunda mutação intelectual, quer no domínio do direito, quer nos domínios ético e moral, assim como apreciar o peso relativo das nuances estratégicas.

Intencionalmente, ou não, as arremetidas contra o edifício tradicional foram deitando abaixo as ameias, num trabalho de erosão que levou tempo e para o qual desempenharam papel insubstituível todas as arremetidas. Eu terei tendência a valorizar o que nessas investidas comporta uma revalorização dos elementos secularizantes, do incenso da razão, teorética ou prática, da promoção da autonomia, independentemente do corpus ideológico que as utiliza como armas e, finalmente, em que circunstâncias e ao abrigo de que estratégias elas são, quer dizer foram, utilizadas. Não há um corpus eficiente, não há uma estratégia decisiva, o efeito global de erosão (arruinamento, desconstrução, desabamento, corrupção, desgaste, desmoronamento, etc.), deu-se a partir de avanços e recuos, corporizou-se nalguns pontos de obras que, em contrapartida, noutros pontos, mostravam uma estreita colaboração com o modelo que sobrevivia e, por vezes, um conformismo decepcionante. Não faz muito sentido voltar Hobbes contra Grócio, ou Pufendorf contra Wolf, ou Samuel Clarke e Thomas Reid contra Hutcheson, ou Cudworth e Shaftesbury contra Locke, ou até Cumberland contra Culverwell e Burlamaqui contra Barbeyrac ou ainda Holbach e Helvécio contra Rousseau ou Voltaire, etc. Porque em todos estes autores e nas suas respectivas obras brilhou uma acendalha atirada contra a tradição.

Se o que nos atrai em Cumberland é, na sua oposição sistemática a Hobbes, o internalismo empírico -- naturalista em que se enquadra, isso não nos pode impedir de reconhecer que, globalmente, o pensamento de Cumberland está ainda minado por um organicismo de fundo e que, face a ele, o Leviathan de Hobbes é infinitamente mais moderno, mesmo se o externalismo voluntarista, em que se fundamenta a obrigação moral, seja um elemento de heteronomia que, em minha opinião, o empobrece.

Se seduz em Clarke, por exemplo, o papel relevante que a razão desempenha na construção do seu edifício moral e se, portanto, a sua clara filiação no intuicionismo moral, com base na razão, elucida sobre uma 
apetência secularizante, já o pouco interesse dado à razão prática e à autonomia do agente no plano dos motivos, colocando-o nesse plano no domínio do externalismo relativamente às motivações, poderia desiludir. E só não desilude porque esse externalismo é congénito com o próprio intuicionsmo racional devedor, nesse plano, à tradição intelectualista antiga e medieval, tradição essa, da qual decorre, com naturalidade, um inevitável determinismo metafísico, onde uma boa parte da autonomia prática fica diminuída. Mas, não se deve confundir este externalismo relacionado com a inexistência de um practical reasoning ao nível da motivação, com o externalismo que, em Locke, imputa a moralidade à positividade das leis com os concomitantes prémios e castigos de clara matriz puritana e, portanto, em última instância, na linha da tradição lutero-calvinista. É que Locke é justamente um dos autores em que o internalismo autonomista ao nível da acção se encontra melhor definido. Parece paradoxal, mas não é. Ou se preferirmos, tudo isto decorre das contradições próprias de um movimento que enfrenta uma sólida tradição, com armas ideológicas distintas. Pensar que a Cultura moderna apareceria, formada, inteira e coerente, como Minerva saída da cabeça de Juno, releva mais da ingenuidade do que propriamente de má fé.

Mesmo assim, e correria o risco de um puro eclectismo argumentativo, eu penso que há uma linha de orientação que, embora desdobrada segundo um esquema multi-centrado e multi-vectorialmente orientado, se coaduna melhor com a tendência daquilo a que se chama por conveniência e genericamente de Aufklärung.

E que consiste, no essencial, na revalorização: A. Da razão, tanto teorética quanto prática «comme la suprême puissance de 1 'homme» ${ }^{1}$, B. do internalismo a todos os níveis: da motivação, da acção, e da fundamentação última da obrigação, C. da secularização, D. da autonomia, ou seja, da

1 Pode parecer presunçoso, mas tenho como adquirido que todas as reinterpretações da Aufklärung centradas na crítica da razão, como é o caso das perspectivas da Escola de Frankfurt e de Michel Foucault, ambas já subsidiárias da leitura proposta pela crítica da metafísica levada a cabo por Heidegger, entre muitas outras, estão estruturalmente erradas, porque exacerbam o papel da razão, ou seja, justamente da faculdade que começou a perder influência logo nos alvores do lluminismo. Assim o que diz Ana Cristina Araújo: "Theodor Adorno e Max Horkheimer (...) Na célebre obra Dialektik der Aufklarüng (1947), os dois filósofos alemães interrogam-se sobre os efeitos demolidores do culto da razão. Em seu entender, o «desencantamento do mundo» provocado pela confiança cega na racionalidade do homem e pela sobredeterminação da ética à lógica totalitária do conhecimento teria conduzido à «auto-destruição da Aufklärung»", (in Araújo 2003: 12), não me parece adequado à reinterpretação que proponho. A destruição da Aufklärung deve associar-se, pelo contrário, à perda de influência da razão, logo nos alvores da Filosofia das Luzes e, em particular, da razão teórica. A substituição de uma ideia de progresso, globalmente humanista, centrada na razão teórica emancipadora e fomentadora do sentido da autonomia, por uma ideia de progresso, meramente empiricista, --- centrada no sentido estreito da utilidade e no pragmatismo material, ancorada, de resto, numa atitude eticamente e metafisicamente heterónoma, --- é que deve ser responsabilizada pelo colapso precoce da aventura libertadora da Aufklärung. 
autonomia da razão, do sujeito e da vida moral, social e política, E. da emergência do indivíduo mas sobretudo do sujeito. Sujeito, quer dizer, subjectum, fundamento da norma mas também sujeição à norma. (O sujeito é o indivíduo que se submete voluntariamente à norma que ele próprio construiu). E tudo isso pressupõe a ideia de Contrato ou Pacto Social. F. Da recolocação da ideia de um progresso global e não de um progresso «comme une simple extension du savoir, comme un progressus in indefinitum», ou seja, de um progresso global contra um progresso quantitativo, simples somatório de progressos empíricos, dispersos, etc. Em síntese, de um progresso unitário «en dehors de toute fin particulière», G. da recolocação do problema do recurso à autoridade ou à sua crítica, à verdade revelada ou à verdade construída, etc. $\mathrm{H}$. Enfim de um reforço da trajectória de afirmação do humanismo.

\section{Os domínios do Eu.}

É para mim um ponto assente que toda a investigação sobre o advento da modernidade deve começar por um amplo excurso sobre a reflexão moral. Eu diria que foi isso que os próprios autores dos finais do século XVII e século XVIII fizeram. E se colocaram como prolegómeno uma prévia investigação sobre a natureza do homem isso aparece de algum modo como tautológico uma vez que nos séculos XVII e XVIII a natureza do homem e a sua natureza moral são, pode-se considerar, a mesma coisa. Isso mesmo se depreende da questão, «What is the role of life?» pergunta nuclear que Joseph Butler fazia logo no prefácio aos seus Fifteen sermons proferidos na Rolls Chapel em 1726.

Perguntar pelo papel da vida é perguntar pelo seu sentido, e pela finalidade do homem dentro desse desempenho, jogando com o duplo sentido de papel. Mas querer saber o papel, o objectivo, o sentido enfim da vida humana, é avançar para a discussão dos pressupostos de uma antropologia fundamental, que o mesmo Joseph Butler disse consistir no lançamento de um olhar prescrutador «to the inward frame of man».

Acontece que procurar as fontes do eu, ou do indivíduo, Sources of the self, como lhe chamou Charles Taylor, não significa procurar uma fonte, porque na modernidade, pela primeira vez, ao contrário do que aconteceu no pensamento clássico ou no pensamento medieval, não há uma fonte, seja ela cosmológica, religiosa, ou mesma humanista no sentido clássico e renascentista do termo.

$\mathrm{O}$ Eu da modernidade aparece no seio de um processo e é o resultado de um complexo de aporias existenciais e filosóficas, e ainda o é nos nossos dias. $\mathrm{O}$ Eu da modernidade é, ao mesmo tempo, uma interrogação e as múltiplas 
tentativas não para responder a essa interrogação mas para a alimentarem. Trata-se portanto de um processo aberto que não visa nunca a unidade. É irónico que podendo acusar-se a modernidade de se reduzir a um processo teleológico e escatológico ou, se quisermos, à secularização das teleologias e escatologias arcaicas, o que melhor a caracteriza é o modo como posterga e arruína todas as teleologias e todas as escatologias, ao mesmo tempo que parece sucumbir ao fascínio que elas representam. Pelo caminho o homem da modernidade foi obrigado a inventar ou a reinventar alguns conceitos, como autonomia, liberdade, indivíduo, pessoa, sujeito, etc.

A polarização tipicamente moderna, bem desenvolvida por Baudelaire a propósito do fenómeno artístico, e bem conceptualizada por Koselleck, em torno do par eterno/ efémero, aniquila ao mesmo tempo a neurose do efémero e a tranquilidade do eterno, de tal modo que a modernidade é teleológica sem ter um fim e é escatológica, mas na perspectiva de que a dimensão escatológica esteja sempre adiada. De facto, as metanarrativas apocalípticas ou as utopias orientadas para fins felizes já não são modernas, uma vez que desistiram da angústia que a modernidade transporta consigo e, desse modo, são portanto formas desgarradas de desistência, destroços que a modernidade deixou e deixa pelo caminho e que o anjo ${ }^{2}$ vê, apenas, porque viaja de costas em direcção ao futuro.

Talvez porque o anjo se divida entre a antevisão dolorosa do futuro e a visão não menos dolorosa dos destroços, coabitam sempre em cada época moderna, e por maioria de razão no advento da modernidade, duas atitudes intelectuais paradigmáticas, uma que corresponde à resignação e outra que corresponde à insatisfação que é a própria essência da modernidade. Isso também corresponde à modernidade posterior. À nossa. A pós-modernidade errou o alvo, ao escolher como alvo, dentro da modernidade, aquilo a que Lyotard chamou de metanarrativas; uma vez que se dirigiu para o que a modernidade oferece como evidência mas não para o lado oculto da cultura moderna, o lado mais íntimo, que é o mais verdadeiro. A modernidade nunca é uma resposta. A modernidade é sempre uma pergunta com resposta adiada.

Ao romper com a circularidade do mito do tempo, mas também com a sua linearidade previsível, ao resolver o enigma dos labirintos através não da experiência vivida mas da razão, instrumento artificial e dessublimado, a modernidade conduziu a humanidade a um processo sem fim, onde, dizem, a própria ideia de sujeito e a sua centralidade se arruinaram e onde a própria 
hermenêutica do fim confere ao ser nostalgia ou desespero. A modernidade é niilista porque esgota o sentido, através de uma inesgotável procura do sentido. É isso que se sente quando se percorre o acervo de textos inaugurais dessa modernidade. Razão tinha Foucault quando afirmava que o Eu da modernidade se dessubstancializa e se torna progressivamente o lugar geométrico das múltiplas formas discursivas. Simplesmente não é essa a sua fragilidade mas a sua força e grandeza. E tenho para mim que esta aventura de desenraizamento radical, ontológico e metafísico, começa onde se enceta a minha investigação. E penso ainda que a ideia de felicidade, pela sua profundidade ontológica, está, como não podia deixar de estar, no centro da grande mutação. A aventura ético-moral, jurídica, social e política do homem moderno é indiscernível dos desafios existenciais, laicos ou religiosos que se lhe colocaram, e a ideia de felicidade tornou-se naturalmente uma ideia-chave.

3. O Neoplatonismo de Cambridge (Cambridge Platonists): Benjamin Whichcote, Henry More, John Smith e Ralph Cudworth.

Alguns autores consideram ainda Nathanael Culverwell e Richard Cumberland como pertencendo, senão ao círculo dos Cambridge Platonists pelo menos ao ideário neoplatónico ${ }^{3}$, ou ao contrário, não é relevante. Mas, embora haja afinidades, maiores no caso de Culverwel, a análise de ambas as obras levou-me a considerar estes autores à margem do movimento neoplatónico inglês. E assim, quando estou a referir-me ao Neoplatonismo de Cambridge estou de facto a referir-me sobretudo a Ralph Cudworth, mas também a Benjamin Whichcote, John Smith e Hery More.

O Neoplatonismo de Cambridge justifica e exige por si uma reflexão aprofundada neste esboço do pensamento ético-moral da protomodernidade porque, penso eu, uma determinada linha de orientação, muito frutuosa relativamente à autonomia, tal como eu a entendo, tem nesta escola de pensamento, um momento inaugural, sobretudo no seio da cultura ético-moral e jurídica inglesa. Tenho para mim que autores como Shaftesbury, William Wollaston, John Balguy, Samuel Clarke, Richard Cumberland e até Joseph Butler manifestam, nas suas obras, uma dívida expressa relativamente aos Cambridge Platonists e sobretudo à sua figura tutelar, ou seja, Ralph Cudworth.

Não quis, contudo, evidenciar este autor em prejuízo dos outros membros do círculo neoplatónico, já que se encontram em todos eles não só elementos 
que culminaram em Cudworth, como alguns elementos estritamente pessoais, mas de grande importância para os autores posteriores, elementos teológicoreligiosos desde logo, mas com implicações éticas, morais e jurídicas. E o pensamento dos neoplatónicos de Cambridge não se compreende desligado do seu carácter apologético, e ao mesmo tempo polémico, contra a tradição dominante da cultura inglesa na mesma época. Estou a referir-me a uma tradição com duas componentes essenciais, o puritanismo e o empirismo ${ }^{4}$.

Durante muito tempo estas duas orientações intelectuais andaram desligadas, mas investigações, ia dizer recentes, e em boa verdade não tão recentes assim, mostraram que elas são duas faces da mesma moeda. O empirismo com a sua dimensão naturalista e sensista e o puritanismo com a sua dimensão teologicamente voluntarista (positivista) e integrista adaptam-se muito bem e adaptaram-se historicamente muito bem. Esta adaptação pareceria estranha a um leitor desprevenido, mas as análises de Ernest Cassirer ${ }^{5}$ e as intuições de Windelband ${ }^{6}$ e Eliade ${ }^{7}$, assim como os últimos desenvolvimentos do pensamento de Charles Taylor ${ }^{8}$ e sobretudo dos neokantianos franceses ${ }^{9}$, entre seguramente muitos outros autores, dissiparam as dúvidas, para mim: O empirismo inglês uniu-se estruturalmente ao que de mais heterónomo e menos humanista se formou na cultura da protomodernidade europeia.

É neste contexto que o pensamento neoplatónico do século XVII ganha uma acuidade insuspeita e merecida. O seu significado, intelectual e sociopolítico, sofre uma metamorfose radical pela contextualização. E não é a primeira vez, e não será seguramente a última, em que o valor intelectual e até o significado, na história do pensamento, de um determinado movimento ou autor é obrigatoriamente reavaliado e adquire um significado que, a priori, parecia não possuir. No limite, pode mesmo sofrer uma torsão de significado. Se não fosse a contextualização, o movimento do Neoplatonismo de Cambridge seria julgado como uma espécie de anacronismo, como aliás faz Cassirer que, a meu ver, não foi ao fundo das implicações que o movimento continha em si do ponto de vista histórico. Ele diz explicitamente que, numa

4 É sabido que a antipatia dos Cambridge Platonists por Bacon não era menor que a antipatia por Calvino. A identificação excessiva da ciência com a técnica não podia deixar de chocar o humanismo dos neoplatónicos de Cambridge.

5 Cassirer, E., The platonic renaissance in England, Nova lorque: Gordian Press, 1970.

6 Windelband, W., History of Philosophy, Nova lorque, 1958.

7 Eliade, M., «La nostalgie du paradis dans les traditions primitives», in Diogène (no 3), Paris, 1953.

8 Taylor, C., Sources of the self: The making of modern identity, Cambridge: Cambridge University Press, 1989.

9 Renaut, A., L'ère de l'individu. Contribution à une histoire de la subjectivité, Paris: Éditions Gallimard, 1989 e Ferry, J.L., Homo Aestheticus, Paris: Grasset, 1990. 
época em que dominavam o Discurso do Método de Descartes e o Novum Organonum de Bacon, a obra de Cudworth parece um anacronismo. O verbo parecer salva o autor de um erro maior, mas o desenvolvimento da sua tese mostra que Cassirer, para lá do génio de ter percebido a legitimidade deste tipo de pensamento, assim como a lógica obscura do pensamento adverso, ou seja do empiro-puritanismo, não logrou atribuir-lhe o valor de que ele era portador.

Eu penso que só hoje estamos em condições de o fazer, hoje, quer dizer, depois da denúncia corporizada na metafísica do sujeito de Heidegger, da crise da razão e da autonomia, denunciadas ambas pela Escola de Frankfurt e, mais recentemente, pela crise global da modernidade e pela emergência de um novo paradigma, mais antropológico e menos sociológico, que a pós-modernidade sublinha, ao mesmo tempo que, paralelamente, uma nova reorientação das filosofias do sujeito procura salvar a razão e o próprio sujeito da morte anunciada que os estruturalismos, de toda a ordem, lhe urdiram e anunciaram. Por isso, hoje estamos em condições de considerar que o neoplatonismo foi tanto um anacronismo como a Escolástica Peninsular havia sido um anacronismo, ou seja, anacronismo nenhum, mas antes, pelo contrário, que este tipo de juízo correspondia ao preconceito de um olhar inquisidor que se colocava à margem da natureza profunda de ambos os movimentos.

Hoje estamos em condições de poder compreender que o Neoplatonismo de Cambridge representou um poderoso esforço para salvar o homem das tenazes da heteronomia mais radical e assim promover uma escapatória humanista e autonomista que, nos seus desenvolvimentos mais consequentes, vai conduzir ao humanismo das luzes e até ao próprio coração da autonomia, ou seja a Kant.

As questões jamais se colocaram com este tipo de clareza esquemática pois, de facto, os inimigos jamais se afrontam no plano da realidade das suas naturezas mas sempre no plano das suas ideologias transcritas, embora, em boa verdade, seja sempre a realidade não confessada que é o móbil secreto do antagonismo e da inimizade. Para o puritanismo tanto quanto para o empirismo os inimigos são a especulação e o espírito contemplativo e os valores dinâmicos a salvaguardar contra os inimigos são a acção e, atrevo-me a dizer, o poder. Acção e poder ligados umbilicalmente à prática, ao real concreto e ao progresso daí emergente. Por isso, para uns a felicidade está ligada à acção enquanto, para os outros, ela está ligada à compreensão. Sabemos o quanto um conceito como o de compreensão era desagradável aos olhos do puritanismo.

Se nos ativermos apenas à espuma das ideias, à sua aparência imediata, seríamos levados a pensar que a filosofia da natureza dos Cambridge Platonists representaria uma regressão. É óbvio que a espiritualização da natureza pode 
ter consequências funestas para o progresso científico, sobretudo se for levada ao extremo de uma recaída numa espécie de panteísmo organicista, onde mergulhou tanto, uma parte significativa da renascença como, mais tarde, o romantismo. Mas, em contrapartida, a completa separação, como fizeram os empiristas, entre a ideias de progresso técnico ligado à instrumentalização da natureza e a compreensão racional e autónoma de um sujeito que se constitui em norma e fundamento para si mesmo, pode conduzir o progresso científico a um processo de reificação, processo esse, que aliena simultaneamente a autonomia do sujeito, a sua auto-compreensão, e a compreensão global do processo científico, pulverizado pela atomização das micro compreensões ligadas à simples amálgama de empiricidades dispersas.

Cassirer afirma que Bacon procede à separação dos domínios do conhecimento e da fé, não para salvar a religião mas, para melhor salvaguardar os domínios dos poderes cognitivos naturais. Ora eu penso justamente o contrário, isto é, que a coligação entre o puritanismo e a experiência, com claro desdém pela razão teórica, significou a defesa intransigente dos valores tradicionais da igreja e de uma fé mantida em cânones repressivos, irracionais e arbitrários, e onde os conhecimentos práticos elaborados na prática científica de tipo empírico não constituíam, por falta de um elemento agregador e sistematizador, pensado e reflectido, uma alternativa global ao poder da Igreja. A condenação da razão é a condenação do único elemento que poderia questionar a arbitrariedade, a irracionalidade e a violência repressiva do integrismo religioso. A desvalorização da razão deixa os dois domínios de tal forma separados e incomunicáveis que não é possível a possibilidade de uma Mathesis Universalis, essa sim, perigosa (preocupante).

Pela razão, pode chegar-se à construção de um sistema intelectual compreensivo que integre a ciência e a fé ou que, pela sua natureza, exclua uma das partes. A possibilidade de o homem pensar à margem dos imperativos estabelecidos, de conferir ao mundo uma lógica e uma finalidade imanentes, de construir (criar) um modelo de mundo e de vida satisfatórios, coerentes, e harmoniosos, no quadro do qual possa resolver as suas finalidades terrenas de realização, de felicidade e de perfeição secularizada, isso sim é que era afrontoso e intolerável, por isso Lutero lhe chamou, a ela a razão, essa grande rameira.

E nem é tanto o perigo que a razão desempenha, enquanto factor de realizações concretas, mas o que ela já significa enquanto prática teórica, enquanto hábito, enquanto crença recorrente e tudo o que nela se coloca, as esperanças, os motivos, enfim o facto de que ela representa a constituição de um novo modelo de vida, de perspectiva, etc. Ela encerra juntamente com o humanismo que lhe está intimamente associado um universo alternativo, 
um universo do conhecimento e dos saberes, que subentendem um Saber, mas também um universo ético-moral alternativo, onde o homem começa aos poucos a desgastar a perspectiva escatológica e a começar a construir, mesmo que não deliberadamente, uma espécie de paraíso na terra, pela via da secularização que o simples uso da razão logra por si.

Não é uma questão de intencionalidade, nem de perspectiva, nem de teleologia, o uso da razão gera mundos, o uso da razão desencanta, torna redundantes as escatologias, numa palavra, o uso da razão seculariza, quer dizer racionaliza e humaniza simultaneamente. Não interessa quais eram os objectivos do Neoplatonismo de Cambridge, os objectivos teológicos e apologéticos, o que interessa é que a revalorização da razão, que se operou nas suas obras, contra a arbitrariedade irracional, promovia um sentido que era globalmente racionalizador.

Tanto o empirismo como o sensismo, estigmatizados ambos por crenças religiosas integristas, temiam, tanto quanto a Igreja, o poder dissolutor da razão. O poder unificador dos saberes empíricos representava um perigo a que não eram alheios os próprios promotores desse tipo de saberes. Se não fosse assim, a ligação entre o empirismo e o puritanismo, e ela não é apenas um fenómeno inglês, teria sido acidental. Ora, eu penso que não foi. De todas as vezes que a Igreja entre os séculos XVII e XVIII se sentiu ameaçada, promoveu esse tipo de coligação, digamos assim. Não se trata de uma teoria da conspiração até porque entendo o fenómeno inconscientemente realizado na época e que só a História das Ideias reconstitui.

Por exemplo, quando Cassirer diz que a desvalorização da razão, relativamente ao seu papel no seio do pensamento religioso, significava para os Cambridge Platonists, não um menosprezo de facto pela razão mas uma desvalorização da religião, e esse é que era o perigo, para mim isso não é nada relevante. Concluir que a preocupação dominante é a religião e não a razão é um falso problema e significa tirar uma ilação discutível. No essencial é mesmo falsa. Se para os Cambridge Platonists é considerado grave, para a religião, que se afirme que ela não depende nem precisa da razão, só pode significar a imensa conta em que os Cambridge Platonists tinham essa faculdade humana. Seja qual for o sentido em que a interpretemos, a valorização da razão, é sempre uma valorização. Em que conta não tinham os Cambridge Platonists a razão se consideravam que a sua ausência representava um empobrecimento da religião, se consideravam, no fim de contas, que a presença da razão nobilitava o fenómeno religioso?

Uma prova, de que o esquema de Cassirer neste ponto é discutível e que, de algum modo, mostra que a valorização da razão ocorria por ela mesma e 
não decorria de um outro pressuposto está, por exemplo, no facto de que o primeiro tutor de Benjamin Whichcote o censurava muito por seguir Platão e Plotino mais do que os evangelhos, e a razão acima do espírito.

É evidentíssimo que está subjacente à valorização da razão pelos Cambridge Platonists, ao ponto de a considerarem insubstituível, uma valorização por tudo o que ela significa, por tudo o que ela põe em marcha, por tudo o que ela promove e desencadeia. Os neoplatónicos de Cambridge são, embora não isolados, pioneiros do processo de emancipação e de autonomia desencadeado pela modernidade.

O próprio mecanismo do poder que está implícito no puritanismo e que se traduz numa absoluta submissão à omnipotência divina, está, se bem que invertido, no pensamento do pai próximo do empirismo moderno, Francis Bacon: The motif scientia propter potentiam («Knowledge for the sake of power»).

Mas o saber que liberta não é poder, é quase imponderável e de uma insustentável leveza. O saber, em vez de ser um poder, é a expressão de todo o não poder que liberta do poder. Este tipo de saber é a simples expressão da liberdade, da assunção de um espírito emancipador, da proliferação de uma artificialidade que desconstrói todos os centros do poder, e que por isso de uma forma radical emancipa, autonomiza, liberta.

A expressão do poder em Bacon é a contrafacção do poder emancipador, porque não emancipa, e como de resto a história do ocidente veio a confirmar, esse poder acorrentou, escravizou e tal não aconteceu como resultado de uma perversão. Esta homologia entre o regnum hominis e o regnum deos, baseiase afinal nos mesmos pressupostos. Omnipotência e redução à neutralidade. Glória de Deus e glória do homem. Na expressão da glória de Deus o homem é reduzido à dimensão de escravo de um domínio cego, autoritário, arbitrário e irracional, o mesmo acontece ao domínio do homem sobre as coisas. Em ambos os casos "it is an absolute will based on power to which faith is subordinated and must blindly submit"10.

É nessa cegueira que consiste uma prática empirista divorciada da razão e da lógica, no quadro das quais deveria ser compreendida. Só enquadrada pela razão e pela consequente compreensão a prática empirista faz sentido. Talvez que tenha sido nisto que se tornou o processo emancipador das luzes e da modernidade, mas o projecto inicial das luzes não subsumia razão e vontade nesse poder cego, implícito no empirismo inglês e no puritanismo. O projecto emancipador das luzes contemplava, simultaneamente, liberdade e autonomia, 
e pressupunha no seu ideário complexo, bondade, benevolência, optimismo, justiça e justamente não um progresso cego mas, pelo contrário, um caminho iluminado pelas luzes da razão.

Por outro lado, adiantarei também que o fatalismo é um contravalor das luzes, uma vez que ele se opõe a um dos pontos essenciais do seu ideário, e que consiste no sentido do aperfeiçoamento, da perfectibilidade que é congénita ao homem e à humanidade, do progresso a todos os níveis e não apenas no plano material e prático. A redução do progresso aos prestadios é filisteísmo, a concepção global de um progresso para a humanidade é humanismo. As luzes são humanistas, mau grado a sentença de Foucault, a todos os títulos muito pouco convincente.

Só para aqueles que viram no poder distorcido da modernidade um poder de salvação consideraram perversa a transfiguração que lhe aconteceu, porque, em boa verdade, o futuro era previsível. O que aconteceu estava latente na própria assunção do saber como poder. Não deixa de ser curioso verificar que estas duas formas do poder continuem juntas nos nossos dias.

A posição dos Cambridge Platonists é completamente adversa desta concepção de poder e de domínio. Para os Cambridge Platonists, tanto o puritanismo como o empirismo brotam de uma ideia de espírito prático estrito dirigido no sentido do domínio sobre o homem e sobre as coisas. Com alguns séculos de avanço eles conduziam uma luta que finalmente se tornou clara. Uma certa interpretação e uma certa tendência imersa na modernidade do humanismo das luzes, conduziu a esta instrumentalização e domínio sobre o homem e sobre as coisas. Há no pensamento dos Cambridge Platonists e na sua luta como que um augúrio da história da modernidade.

\subsection{Whichcote, More, Smith e Cudworth.}

"What is contrary to the order of reason, is contrary to the state of nature". Benjamin Whichcote

Não seguirei os passos da apologética própria dos Cambridge Platonists, embora até nessa atitude teológica se desenhe muito bem o sentido do pensamento que interessa mostrar, mas apenas porque isso seria moroso. E portanto estarei mais atento aos aspectos ético-morais em sentido estrito.

No Enchiridion Ethicum, More sustenta que a virtude não é um hábito mas um poder e, à boa maneira estóico-cristã, um poder de governo sobre as paixões, situado na parte intelectual da alma, agora à boa maneira platónica. No entanto, depois, cai numa aparente contradição quando afirma que as paixões são anteriores a qualquer deliberação e, desse modo, elas são portanto anteriores ao trabalho racional da proaíresis ( $\pi \rho 0 \alpha 1 \rho \varepsilon \sigma 1 \varsigma)$, e sendo anteriores 
à razão elas são ainda parte da natureza. Elas são natureza. Se a natureza é obra de Deus, elas vêm de Deus e são portanto inevitavelmente boas, porque toda a criação é boa. Então elas estão de acordo com as leis da natureza. E se as leis da natureza são o murmúrio da voz de Deus dentro de nós e portanto o murmúrio da própria lei divina, não haveria lugar para a necessidade de um governo sobre as paixões. Mas o autor considera que o murmúrio de Deus é mais audível na razão, no nosso estado intelectual, e assim é como se a razão ouvisse primeiro a voz de Deus. Daqui decorre já toda a precedência da razão assim como a sua capacidade de liderança.

Do ponto de vista de uma ética cognitiva More coloca-se imediatamente no plano cognitivista e de um cognitivismo puramente intuicionista.

Os Ethical Noemata são verdadeiros axiomas morais, tão válidos quanto os axiomas geométricos, porque permitem o acesso imediato a verdades morais ou essências morais auto-evidentes e imutáveis. Eles são portanto verdadeiras primeiras verdades. O pensamento de Descartes desempenhou, como se infere, um papel determinante em More e em quase todo o Neoplatonismo de Cambridge. O intuicionismo moral de More reforça-se através da concepção da boniform faculty e alguns autores viram nela uma prefiguração do Moral Sense. Mas a meu ver é tanto uma prefiguração do senso moral quanto da razão moral, uma vez que ela representa uma espécie de divina sagacidade, embora o que mais interesse seja o carácter de intuicionismo moral que inequivocamente inaugura. Acrescento ainda que se o Neoplatonismo de Cambridge influenciou o senso moral e a razão moral não influenciou menos a consciência moral de Butler. Enfim, este é apenas mais um aspecto em que o Neoplatonismo de Cambridge deixou marcas profundas e duradouras.

Mas, talvez que ainda mais importante do que o intuicionismo moral importa de facto o sentido de uma agency, prática norteada por essa mesma boniform faculty, no sentido de um envolvimento com a felicidade individual. A definição de ética para More é já em si muito esclarecedora: "ars bene beatque vivendi" ${ }^{11}$, sendo que, nesta linha de orientação, ele define assim a felicidade: "beatitudi est voluptas quam animus percepit ex sensu virtutis, rectaque (et ad virtutis normam) factorum conscientia"12. E é este sabor finalístico e eudemonístico que afasta More do seu mestre Cudworth cujo transcendentalismo aproxima mais de Kant, como se há-de ver. A íntima conexão entre felicidade e virtude, em More, matiza o seu intelectualismo

11 Henry More [Ethica Noemata, Livro I, Cap. I]. (arte de viver segundo as virtudes = arte de viver beatamente, virtuosamente)

12 Henry More [Ethica Noemata, Livro I, Cap. II, § 2]. 
e, através da boniform faculty, introduz toda uma dimensão do sensível com contornos vagamente hedonísticos. E essa capacidade de gozo moral reside "in facultate animae Boniformi, nempe in ea facultate qua sapimus id quod simpliciter et asolute optimum est, eoque unice gaudemus"13.

Whichcote evidenciou a importância decisiva destes primeiros princípios, destas evidências racionais imediatas, de uma forma muito sugestiva, ao afirmar que "We know in reason, that first principles are self-evident, must be seen in their own light, and are perceived by an inward power of nature. For, as we say, out of nothing comes nothing; so, grant nothing; and nothing can be proved" 14 . Há um ponto em Whichcote ao qual sou dado a atribuir uma enorme importância e que consiste no facto de que, para este autor, a moralidade é por si suficiente para que se possa ganhar a salvação. Formulação que anda próxima do pelagianismo e que confere ao ser humano um enorme protagonismo no seu processo salvífico. Claro que se pode dizer que esta afirmação não pode ser descontextualizada do facto de que Benjamin Whichcote considera a moralidade como uma espécie de coração da religião. Sem dúvida que esse pormenor faz muita diferença, mas não fará menos o facto de que o nosso pensador considera que a moralidade deve ser conhecida pela razão e não através do apelo à autoridade, incluindo a autoridade Bíblica. E ainda que, se vivermos de acordo com as leis morais poderemos ser verdadeiramente felizes, aliás podemos até deificar-nos ${ }^{15}$ através de obras virtuosas. Mas o mais relevante, e o que mais me interessa a mim é o facto de que o autor reconhece a existência, em nós, de uma espécie de soberania «over ourselves», que está na base de um poder de autonomia a todos os títulos relevante.

Finalmente, e é lapidar em Whichcote, e exprime não só a dignidade da razão mas o seu carácter insubstituível: «We are not taught, but made to know». Penso que é de todo o interesse e vale portanto muito a pena ler a sentença no seu contexto:

13 Henry More [Ethica Noemata, Livro I, Cap. II, § 5].

14 Whichcote [The use of reason in matters of religion], in Patrides, C. A., The Cambridge Platonists, Cambridge, Harvard University Press, 1970, p. 47.

15 "But to speak, now, of the great Benefits that accrue to us, by our Saviour's being in our Nature. He doth acquire the Right of Redeeming us; and makes Satisfaction in that Nature that had transgressed: And, he doth repair the ruined Nature of Man; by dwelling in it, and by working Righteousness in it: by which means he hath wrought our, all Malignicy, and naughicy Habits, by contrary Acts; the Acts of Sin and Vice, by Acts of Virtue and Goodness; the Acts of Intemperance, by Acts of Sobriety and Temperance. Now, let us look for the Explication of this, in our selves; in our Nativity from above; in Mental Transformation, and DEIFICATION. Do not stumble at the use of the Word. For, we have Authority for the use of it, in Scripture. 2 Pet. 1.4. Being made Partakers of the Divine Nature; which is in effect our Deification. Also, let it appear in our Reconciliation to God, to Goodness, Righteousness, and Truth; in our being created after God, in Righteousness, and true Holiness", cf. Benjamin Whichcote [The manifestation of Christ and the Deification of man], in Patrides, C. A., The Cambridge Platonists, Cambridge: Harvard University Press, 1070, pp. 69 e 70. 
"Thus Scripture represents the State of Man's Creation; that it is the proper Employment of Mind and Understanding, to seek after God, to act our Faculties, to feel God. Therefore it is the Depth of Degeneracy, to be without God in the World; to have God far from our Remembrance. There is a natural and indelible Sense of Deity, and consequently of Religion, in the Mind of Man. Neither is there any Plea or Apology for the want of this. For there is no invincible Difficulty; no Ignorance: We are not taught, but made to know. There is no Impotency: For every one can use the Parts of Nature; at least, when at Age. There is no Impediment: For it is transacted within ones self: Not subject to be Control of any Usurper. For, an internal Elicit Act is exempt from all the World: And may be done by the Mind, which is at liberty; when the Person is under restraint" ${ }^{\text {.6. }}$

Há um laço interno entre a moralidade e o Eu. Deus fez-nos para conhecermos o modo de aceder a Deus, deu-nos as faculdades sólidas e de confiança para o conseguirmos, além de que nos criou de tal modo que a moralidade se nos torna como que inerente. Ser moral é ser racional. A imoralidade é desrazão. E é assim, de tal modo, que ser salvo se torna simplesmente uma consequência de viver de acordo com aquilo que nós próprios vemos como sendo certo. Só assim faz sentido a religião e a moralidade ${ }^{17}$.

Penso que é nesta dicotomia, que é possível estabelecer, entre uma moralidade imanente e uma moralidade transcendente, que se abre a grande avenida por onde há-de passar a modernidade. E é claro que esta bipolarização determina uma outra dualidade, não menos relevante, voluntarismo / autonomia. E é desde a Escolástica Peninsular que, passando pelo Neoplatonismo de Cambridge, este caminho se começa a desenhar. Ainda que alguns autores recuem esta genealogia até $\mathrm{S}$. Tomás, através das causas segundas, penso que tal é inadequado. Em S. Tomás - e apesar da importância atribuída à razão e apesar da mundanização implícita nas causas segundas - há pelo menos três elementos que são avessos à autonomia. A ideia de regula (régua e regra) para o comportamento moral funciona como uma muleta, sem ela o homem escreveria torto, ou seja, errado. Em segundo lugar desprende-se, no plano antropológico, uma espécie de determinismo metafísico essencialista através do qual, obedecendo o homem ao telos da sua natureza, o homem tenderá naturalmente para o bem, quer dizer para a sua perfeição, ou seja para a felicidade. Esta injunção: perfeição (bem e felicidade), natureza, virtude, confere um sentido holista à vida moral que não pressupõe um arreigado

16 Whichcote [The use of reason in matters of religion], in Whichcote [The manifestation of Christ and the Deification of man], in Patrides, C. A., The Cambridge Platonists, Cambridge, Harvard University Press, 1970, pp. 69 e 70. Patrides, C. A., The Cambridge Platonists, Cambridge, Harvard University Press, 1970, pp.59 e 60.

17 Whichcote [The use of reason in matters of religion], in Patrides, C. A., The Cambridge Platonists, Cambridge, Harvard University Press, 1970, pp 59 e 60. 
sentido da autonomia. Finalmente, falta ao pensamento aquiniano e como consequência do que acabei de dizer, um princípio regulador individual que sendo racional é de ordem prática e que assim acentua o sentido internalista e autonomista das decisões morais.

As convicções anti-voluntaristas, associadas à constitutiva bondade das criaturas, homóloga da bondade divina, e ao papel determinante da razão que nos foi atribuída com o triplo papel de conhecer, de aceder a Deus e de governar a nossa moralidade, conferem ao pensamento dos Cambridge Platonists a sua originalidade e encontram-se sistematicamente estruturados no pensamento de um deles, Ralph Cudworth, de uma forma tão original, que fazem deste autor o grande pensador da autonomia nas vésperas da modernidade. É claro que nem tudo aparece em Cudworth, e nunca é demais insistir no facto de que a defesa intransigente da razão é comum a todo o grupo, e desde logo ao seu fundador. De facto, encontram-se em Whichcote formalizações, como as que vou referir que, sendo complementares, resumem bem tudo o que está em jogo: "If Reason did not apprehend God; Religion could not be learn'd", e "If God had not made Man to know there is a God; there is nothing that God could have demanded of him"18.

Mas, não é exagerado afirmar que é no internalismo autonomista de Ralph Cudworth que todo o sentido da autonomia se consagra. Aliás, o internalismo autonomista de Cudworth é mais do que autonomista. É mesmo um internalismo de auto-determinação que anuncia a revolução ético-jurídica neste domínio. Daí a sua importância absoluta e relativa. Mas é justo que se diga que também este sentido da autonomia foi comum a todos os membros do movimento, se é que de movimento verdadeiramente se tratou.

\subsection{Ralph Cudworth}

\subsubsection{Introdução}

Mallum actum malum esse nisi quatenus a Deo prohibitum, et qui non possit fieri bonus, si a Deo praecipiatur; et e converso. Ockham.

Se eu precisasse de uma referência, entre muitas, para situar a batalha intelectual conduzida por Ralph Cudworth, este excerto de Ockham, retirado da própria obra do neoplatónico inglês do século XVII, assentar-lhe-ia 
como uma luva. É claro que os inimigos ideológicos estavam muito mais próximos e eram os puritanos ingleses da mesma época, mas a verdade é que a fundamentação do puritanismo é, pelo menos, tanto lutero-calvinista, quanto occamista.

Mas, sabe-se que desde a Escolástica Franciscana e até já antes através do magistério de Santo Anselmo se começou a recuperar um património que pode ter começado com S. Paulo e foi seguramente desenvolvido pelo Santo Agostinho das obras posteriores às Confissões e que encontrou a mais desvairada formalização com a reforma. Esse património estabelece um nexo indissociável entre, por um lado, a tradição voluntarista e a omnipotência divina e, por outro lado, com o positivismo da obrigação jurídica.

A ele não foram insensíveis autores como Hobbes e Locke e dominou, concretamente, a tradição intelectual portuguesa setecentista. Em Portugal, é um domínio suave e mitigado, mas é um domínio. O que eu quero dizer é que há mais voluntarismo teológico que intelectualismo teológico na cultura portuguesa do século XVIII. Há mais Santo Agostinho do que S. Tomás de Aquino. Muito provavelmente, a luta contra a escolástica e contra o aristotelismo produziu colateralmente esta consequência. Consequência perversa, atrevo-me a dizer.

Desde, pelo menos, o franciscano Roger Bacon que a esta ideologia teológico-metafísico-jurídica se acrescentou um elemento empíriconaturalista e sensista, com particular ênfase no sentido prático e utilitário dos saberes, acompanhado também invariavelmente por uma suspeição, a meu ver suspeita, acerca dos poderes da razão. Este dispositivo, aqui esquematicamente esboçado, encontra, nas vésperas da modernidade e dentro já do século XVIII, um papel nuclear no combate intelectual contra as formas mais ousadas da secularização, tanto no domínio ético-moral, como no domínio estritamente jurídico-político.

Em conformidade com este esquema, interessa-me sobremaneira evidenciar, para a mesma época, todas as reacções sistemáticas ao modelo. Não me interessa se a propedêutica é de natureza teológica ou laica. Onde quer que o pensamento se tenha entrincheirado para combater o pessimismo ontológico $^{19}$, a heteronomia alicerçada na desvalorização da razão, a

19 Sendo que esta luta atravessa todo o século XVII. Embora não se justifique uma abordagem detalhada da obra moral de La Rochefoucauld (1613-1680), justifica-se aqui uma pequena nota, uma vez que na sua pena o tema do pessimismo atingiu uma altura inédita. A sua denúncia das diversas máscaras do amor-próprio atingem momentos de grande brilhantismo intelectual e fazem pensar nos primórdios de uma moral da suspeita que assim poderia ombrear com as hermenêuticas da suspeita que, contudo, só aparecerão no século XIX, com Schopenhauer, Nietzsche e Freud. O mau amor de si, ou filaucia, é 
redução do processo soteriológico à arbitrariedade da Graça e finalmente a condenação da felicidade terrena, e onde quer que, pelo contrário, se tenham promovido as faculdades próprias do homem, a autonomia centrada na racionalidade, a bondade intrínseca de Deus e a possibilidade humanista da salvação transcendente e da felicidade terrena, estão encontrados para mim os precursores da tradição emancipadora das luzes.

Neste acervo genealógico, o pensamento dos Cambridge Platonists desempenha um papel notável e nuclear e, dentro dele, o pensamento específico da sua figura mais proeminente, a saber, Ralph Cudworth.

\subsubsection{Intelectualismo e voluntarismo}

Vou voltar à epígrafe de Ockham. Ela diz textualmente que nenhum acto é mau se não for proibido por Deus, e que também não se torna bom se não for por Deus ordenado. E assim esta epígrafe sintetiza tudo o que Cudworth resolveu atacar sem desânimo. Mas não bastava ao platonizante autor do século XVII limitar-se a criticar o voluntarismo, enredando-se em intermináveis quezílias teológicas. Ele percebeu que o que suporta o voluntarismo é uma antropologia e uma linha de orientação ética e moral, dela decorrente.

E uma vez que a linha que conduziu à formalização moderna do voluntarismo, nomeadamente em Hobbes mas também em Locke e até em Pufendorf, se bem que neste autor de uma forma mais ambígua, radica numa concepção não essencialista da natureza humana e das próprias coisas, chegando-se a promover um relativismo próximo do cepticismo e do niilismo, Cudworth tomou-se de brios e ultrapassou-se na promoção de uma natureza eterna e imutável das coisas.

Uns dizem que o bem e o mal, o justo e o injusto só existem pela lei e não pela sua natureza, seja ela qual for. Outros acrescentam que não há nada que seja absoluta e intrinsecamente bom ou mau, ou ainda justo e injusto, anterior a qualquer decreto, ordem ou proibição positiva de Deus.

desmontado segundo todas as suas máscaras. O carácter dissimulado dos vícios, o seu modo de se confundirem na composição das virtudes, tudo isso atinge em La Rochefoucauld uma finura que deixa a perder de vista o esquematismo do pessimismo teológico, no qual este autor achou por bem não se meter, embora seja evidente que a oposição agostiniana, entre o amor sui e o amor Dei, esteja como que adquirida e suposta, assim como a dualidade da condição humana na sua situação pré-lapsária e póslapsária. E é também óbvio que, apesar do autor não se debruçar explicitamente sobre questões jurídicas que envolvam a questão da obrigação, está também igualmente subentendida uma radical heteronomia. Em carta a Jacques Esprit, ele chega a acentuar que é pedagógico o exagero sobre o carácter humano assim como a enfatização das suas merecidas misérias, para que através da humilhação sistemática do ridículo orgulho humanista se possa estimular a consciência da necessidade de encontrar apoio no cristianismo. Mostrando a precariedade do homem, entregue a si próprio, salienta-se a necessidade de ter sempre em conta as directivas cristãs. 
Mostra Cudworth, através de um acervo muito razoável de exemplos na história do pensamento e da cultura que, desde Platão (na nossa cultura), estas posições se tornaram habituais. Na tradição pagã estas posições foram protagonizadas por Cálicles e Trasímaco, no Górgias e na República, mas também por Protágoras no Teeteto, Polus no Górgias, e Glauco no Político. Se acrescentarmos a estes nomes os de Aristipo de Cirene, fundador da escola pós-socrática mais consistentemente promotora do hedonismo como filosofia de vida e outros como Demócrito, Pirro o fundador da escola céptica, Carnéades fundador da Nova Academia nos séculos III e II a. C., altura em que culminou, no seio dos académicos, a orientação céptica, que havia começado com Arquesilau na Academia Média durante o século IV e III a. C.; tem-se uma perspectiva, suficientemente ampla, para perceber que este tipo de posições corresponde à orientação de escolas de pensamento marcadas por ideologias relativistas e/ou cépticas. Assim aconteceu com os sofistas, os retóricos visados por Sócrates e, ainda, as escolas pós-socráticas, sobretudo as helenísticas, já numa época de extensa crise da polis.

Salvaguardo aqui a posição de Epicuro uma vez que me parece que a devo colocar noutro plano e assim à margem do cepticismo e relativismo dominantes:

"Pour tous ceux des êtres vivants qui n'ont pas pu passer de contrat sur le point de ne
pas faire de tort mais de n'en pas subir non plus, à l'égard de ceux-là, rien n'est juste
ni injuste ; de la même façon aussi à l'égard des peuples qui n'ont pas pu ou n'ont
pas voulu passer de contrat sur le point de ne pas faire de tort ni d'en subir. (...) La
justice n'est pas un quelque chose en soi, mais, quand les hommes se rassemblent, en
des lieux, peu importe, chaque fois, lesquels et leur grandeur, un certain contrat sur le
point de ne pas faire de tort ou de ne pas en subir"20.

A ideia de Pacto ou de Contrato superioriza-se a tudo o resto. Epicuro não se refere ao problema do bem e do mal, apenas à justiça, e intui-se que não estamos na ombreira de uma ideia absoluta de justiça mas da justiça relativa à polis e à vida social. A posição de Epicuro, até pelo que eu disse, é de uma estranha modernidade e actualidade. Exemplos como este permitem-me dizer que o neo-epicurismo na Europa no século XVII alcançou uma dimensão muito apreciável, através da obra de Gassendi mas não só.

Mas vou voltar a Cudworth. Como eu estava a dizer, o autor sentiu a necessidade de uma propedêutica ontológica fundamental através da qual pudesse erguer a sua epistemologia moral essencialista. Ou seja, partir do 
facto de que existe uma natureza nas coisas, ou de que as coisas possuem uma natureza o que é o mesmo, de que elas possuem portanto uma essência, e que essa essência ou natureza é eterna e imutável e ainda, uma vez que é esse o objectivo central, que é da sua apodicticidade que dependem as propriedades morais. Ou seja, que a moralidade deriva de uma natureza e não de uma normatividade positiva e arbitrária ${ }^{21}$. Neste ponto, reconheço, Cudworth mantém-se muito ligado ao legado aristotélico-tomista. É por isso que ele considera que, e é todo o objectivo do capítulo II do seu tratado, existem coisas que o são por natureza, e sendo assim, entidades como o bem e o mal, o justo e o injusto "(...) cannot possible be arbitrary things made by will without nature, because it is universally true, that things are what they are, not by will but by nature" 22 .

Esta é a base de todos os desenvolvimentos ulteriores e por isso o autor renova esta convicção reiteradamente sob muitas formas proposicionais (elocutórias): Nomeadamente que "is impossible anything should be by will only, that is, without a nature or entity, or that the nature and essence of any thing should be arbitrary"23; ou ainda e finalmente que, apesar de todas as coisas serem criadas por Deus e de Deus dispor de uma vontade plena de poder e de uma ilimitada capacidade para ordenar, mesmo assim, "(...) yet when things exist, they are what they are, this or that, absolutely or relatively, not by will or arbitrary command, but by the necessity of their own nature" 24 . Até porque, e já se sabia, o próprio Deus "cannot supply the place of a formal cause" 25 , embora ele seja a suprema causa eficiente. Mas Cudworth, no auge do seu intelectualismo anti-voluntarista, já disse o mesmo de uma forma mais parecida com a célebre formalização dos autores que mais o influenciaram, Grócio e de uma maneira geral a Escolástica Peninsular: "Neither can Omnipotence itself To speak with reverence by mere will make a thing white or black without whitness or blackness, (...) Or, to instance, in geometrical figures, omnipotence itself cannot by mere will make a body triangular without having the nature and properties of a triangle in it" ${ }^{26}$.

21 la dizer, uma construção artificial do espírito. Mas isso seria injusto, uma vez que há menos construtividade nas posições voluntaristas e positivistas, do que em Cudworth ou Kant e, de resto, em toda a tradição intelectualista. O facto de exisir uma essência não inibe a ideia de artificialidade, nem a ideia de construção, bem pelo contrário.

22 Hutton, Sarah (ed.), Cudworth: A treatise concerning eternal and immutable morality, with a treatise of freewill, Cambridge, Cambridge University Press, 1996, p. 16.

23 Ibidem, p.17.

24 Ibidem, p.17.

25 Ibidem, p.17.

26 Ibidem, p.:16 e 17. 
E nada disso apoquenta o nosso autor uma vez, que como refere Schneewind, "It is not limiting God's power to say that he can do only what is not self-contradictory", argumento forte sem dúvida e que se reforça porque acrescenta logo que "God's wisdom is as much a part of God as his will, so if the latter is limited by the former, God is still not controlled by anything external to himself"27.

Schneewind limita-se aqui a fazer uma paráfrase bem lograda do $\S 7$, do cap. III, do Livro I. Mas eu prefiro este tópico desta parte da obra de Cudworth onde ele diz liminarmente,

\begin{abstract}
"Wherefore as for that argument, that unless the essences of things and all verities and falsities depend upon the arbitrary will of God, there would be something that was not God, independent upon God (...) there is no other genuine consequence deducible from this assertion, that the essences and verities of things are independent upon the will of God. Now the wisdom of God is as much God as the will of God. And whether (which) of these two things in God, that is, will or wisdom, should depend upon the other, will be best determined from the several natures of them"28.
\end{abstract}

E, não pode haver dúvidas sobre isso, é totalmente compreensível que seja a vontade a submeter-se à sabedoria. Até porque, e Cudworth não enjeita para o caso o léxico neoclássico, "For wisdom in itself hath the nature of a rule and measure, it being a most determinate and inflexible thing. But will being not only a blind and dark thing as considered in itself, but also indefinite and indeterminate, hath therefore the nature of a thing regulable and measurable"29. E portanto, vai longa a citação, o mais normal é que seja a faculdade dotada do sentido do limite, da medida e apetece dizer, da proporção e da harmonia que deve regular a faculdade à qual tudo isso falta e que portanto contém em si o ilimitado, a ausência de bornes, de medida, etc. Se nos lembrarmos o que tudo isso significa, arqueologicamente falando, pode concluir-se, sem que isto represente um salto no escuro, que é natural que seja o bem a regular o mal, uma vez que o bem e a bondade são o domínio do limite e da medida.

Mais tarde ou mais cedo Cudworth daria o salto que desde o princípio se adivinha, ou seja, a fundamentação do direito. E se até aqui a luta foi conduzida contra o voluntarismo moral agora o inimigo é o positivismo conexo.

27 Schneewind, J. B., The, invention of autonomy. A history of modern moral philosophy, Cambridge: Cambridge University Press, 1998, pp.207 e 208.

28 Hutton, Sarah (ed.), Cudworth: A treatise concerning eternal and immutable morality, with a treatise of freewill, Cambridge, Cambridge University Press, 1996, P. 26.

29 Ibidem, P. 26. 
Todo o $§ 3$ do capítulo II do Livro I não é mais do que uma paciente condução de argumentos para deslocar a hierarquia das leis com o objectivo claro, primeiro, de subalternizar o direito positivo relativamente ao Direito Natural e, depois, inverter o nexo de causalidade entre a justiça e a lei, no sentido de que as coisas são ordenadas porque são justas e nunca que sejam boas pelo facto de que sejam ordenadas. Quer dizer, a lei vem ao encontro de uma justiça que lhe pré-existe e não é portanto a lei que inaugura o domínio da justiça e estabelece a fronteira entre o bem e o mal. Há uma consciência do que é certo e errado, bom e mau, justo e injusto e a lei limita-se a dar corpo formal a essa verdade e dimensão coerciva à obrigação que está imediatamente nas consciências e não a ideia peregrina de que é a lei --- através da emergência da sua formalização, essa erupção normativa vindo do nada acrescentada à força coerciva, que o lawgiver lhe conferiu --- que determina a justeza ou não do comportamento humano. A adequação ou inadequação está na natureza das coisas como viu Cudworth e depois dele todos os intuicionistas morais, que reconhecem não só a essência da moralidade mas ainda a existência de uma faculdade própria para a perceber, uma vez que não haveria adesão sem essa compreensão.

É curioso que o intucionismo moral de um Cudworth se simplificou através dos epígonos, sejam os defensores do intuicionismo racional, Wollaston, Clarke, Balguy, Price, Malebranche e Leibniz, quer os defensores do senso moral, e não descrimino o sentimentalismo moral ou o senso moral de razão prática, Shaftesbury, Butler, Hutcheson, Reid, Hume, Smith. Em Cudworth a razão teórica é acompanhada de uma razão prática responsável pelo tipo muito particular de intuicionismo e de internalismo autonomista que caracteriza o seu pensamento moral.

\subsubsection{Transcendentalidade e Autonomia}

Mas é pela epistemologia transcendental que devemos começar. Se bem que seja da autonomia que eu quero traçar os contornos decisivos e seja portanto ela o móbil, por excelência, da minha reflexão preliminar à consideração da ideia de felicidade no âmbito do universo mental da protomodernidade, começo e bem pela transcendentalidade.

É que a posição de Cudworth, até pelo seu essencialismo eterno e imutável, favorece uma epistemologia da transcendentalidade, que o autor exprime de múltiplos modos semânticos: «a priori», «proleptically», «Inward antecipation of the mind», «that is native», «domestik», etc., enfatizando todo um acervo de elementos que constituem «condições de possibilidade» que residem, desde sempre, na própria essência do agente. Todo o capítulo III 
do Livro III é a defesa da transcendentalidade e seria demasiado especioso trazer ao meu texto todas as formulações inequívocas desta orientação. Aprazme registar aquela que em minha opinião mais se aproxima da formalização kantiana: "Knowledge is a comprehension of a thing prolleptically, and as it were, a priori" 30 , formalização que foi ao ponto de identificar o objecto com o sujeito, "the intellect and the thing Known are really one and the same"31.

À semelhança de Kant, a transcendentalidade conduz Cudworth, no plano moral, para o domínio prático da motivação. Em Kant, a razão pura prática será levada à construção de um imperativo categórico em que a motivação é apenas formal e em Cudworth será o amor que aparece como fonte universal de motivação. Cudworth desenvolveu o papel do amor num sermão pregado na Câmara dos Comuns em Westminster em 31 de Março de 1647, mas o texto é mais apologético que filosófico. Diz, contudo, coisas importantes relativamente ao seu pensamento. Por exemplo que o amor tal como Cristo pregou aos seus discípulos e que Cudworth cita a partir de versos paulinos (Coríntios I) e joaninos (João 4), é "the source of true happiness"32; que "truth and love, are two the most powerful things in the world, and when they both go together, they cannot easily be withstood. The Golden Beams of truth, and the Silken cords of love, twisted together, will draw men on with a sweet violence, when they will or no" aqui ${ }^{33}$.Enfim, há aqui uma sábia mistura de caridade e eros platónico na génese deste entusiasmo. E finalmente, para já, "let this soft and silken knot of love, tie our Hearts together, though our heads and aprehensions cannot meet, as indeed they never will, but always stand at some distance off from another" 34 .

Tudo isto é apologético e tem o sabor de um sermão mas lá mais para o fim o discurso adensa-se intelectualmente e vale a pena citar longamente uma vez que toda a fundamentação do papel moral do amor assim como o espaço de autonomia que abre no agente moral o justifica:

"I do not here urge, the dead law of outward works, which indeed if it be alone, subjects us to a state of bondage; but the inward law of the Gospel, the law of the spirit of life, then which nothing can be more free and ingenuous: for it doth not act us

30 Hutton, Sarah (ed.), Cudworth: A treatise concerning eternal and immutable morality, with a treatise of freewill, Cambridge, Cambridge University Press, 1996, P.:60. É hoje considerado praticamente indiscutível que Kant terá lido Cudworth e sido influenciado pelo seu transcendentalismo larvar. Cf. Darwall, TheBritish Moralists and the Internal 'Ought' (1640-1740), Cambridge: Cambridge University Press, 1995, p.124.

31 Hutton, Sarah (ed.), Cudworth: A treatise concerning eternal and immutable morality, with a treatise of freewill, Cambridge, Cambridge University Press, 1996, P.:60.

32 Patrides, C., Cudworth , A sermon preached before the House of Commons, em 1647, 1970, p.117.

33 Ibidem, p.118.

34 Ibidem, p 121. 
by principles without us, but is an inward self-moving principle, living in our hearts. I do not urge the law written upon tables od stone without us (though there is still a good use of that too) but the law of holiness written within upon the fleshly tables of our hearts. (...) They that are acted only by an outward law are but like neurospast; (...) But they that are acted by the new law of the Gospel, by the law of the spirit, they have an inward principle of life in them, that from the centre of it self, puts forth it self freely and constantly into all obedience to the will of Christ. (...) The law that I speak of, it is a law of love, which is the most powerfull law in the world; and yet it freeth us in a manner from all law without us, because it maketh us become a law unto our selves. (...) Love is at once a freedome from all law, a state of purest liberty, and yet a law too, of the most contraining and indispensable necessity"35.

Bastou que entre outras pérolas o autor tenha deixado escapar esta, «a law unto our selves» para ter valido a pena a leitura do texto. A lei do amor é o imperativo categórico de Cudworth, fonte de toda a moralidade e, tal como para Kant, ela encerra o princípio da mais radical autonomia. Só o internalismo absoluto desta concepção que passava pela rejeição total do modelo externalista do voluntarismo positivista poderia augurar todo o sentido da emancipação, da liberdade e da autonomia.

Ralph Cudworth voltará a fomentar o espírito de autonomia no seu tratado sobre o livre arbítrio, através da recuperação de uma conceptualização estóica. Em particular o conceito de eph'hemin. E que significa «as coisas que nos são atribuídas», mas que ganhou ao longo da história do pensamento uma conotação com a autarcia e a autonomia no sentido de que ao homem estão designadas, tanto na vida social quanto na vida moral, responsabilidades relativamente às coisas que estão no seu poder, in nostra potestate. E isso é que é a autonomia, o reconhecimento de que reside nas capacidades intelectuais e volitivas do homem uma possibilidade de autodeterminação, ou seja, a assunção de uma capacidade de eleição e de realização próprias. É nisso que reside a valência emancipadora do sapere aude.

Nos estóicos a expressão tinha sobretudo a denotação de uma responsabilidade moral mas não se lhe pode retirar o sentido de que aí se alimenta um forte sentido da autonomia. Uma autonomia que reconhece implicitamente outras instâncias de poder e decisão mas que afirma que há coisas e domínios que nos estão adstritos. Há assim o que está no meu poder e o que não está, o que depende de mim e o que não depende, o que me está distribuído e o que não está, aquilo de que sou ou posso ser responsável e aquilo de que não sou nem posso ser, etc. 
Apesar de residir no intelecto puro a dimensão sensível e afectiva do amor universal, isso não implica que não possa ser gerido, em qualquer circunstância, pela razão prática, pelo contrário, a impetuosidade do sentimento amoroso impetuosidade clamada pelo próprio Cudworth, como se viu atrás, - exige uma faculdade própria. Em Deus, ser dotado de toda a perfeição, a regulação é uma auto-regulação. A razão prática em Deus é uma razão prática pura. Os seres imperfeitos necessitam de uma capacidade de auto-governo, de autoregulação. É aí que aparece o autexousious power. O autexousious power

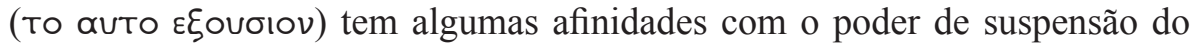
juízo e da acção que o autor promove como momento decisivo na procura das soluções práticas.

Sem mais. Mas também se sabe que a necessidade do uso do poder de auto-determinação, sobretudo quando converge com a imperfeição das criaturas, costuma aparecer como um indício de falibilidade e de fraqueza. Não é o caso agora.

Ela, a necessidade, é o pretexto para a autodeterminação, a oportunidade para o agente exercer a liberdade e a autonomia, valor maior de uma filosofia que anuncia o fim das muletas externalistas. Ele, o poder de autodeterminação, é mesmo o poder de autonomia. E, sendo o órgão do poder da autonomia, ele é também o garante das escolhas que garantem ao agente o caminho para a felicidade.

Mas é o amor que coloca o agente no caminho da felicidade e é o amor que mobiliza a razão pura prática através do seu órgão de autodeterminação, o autexousy power. Por tudo isto se percebe o carácter central do Amor na moralidade de Ralph Cudworth. Ele é o nexo entre a razão teorética e a razão prática. Ele é o motivo ético fundamental. A moralidade em Ralph Cudworth, e isso é extensível ao resto do círculo dos Cambridge Platonists, começa e acaba com o Amor.

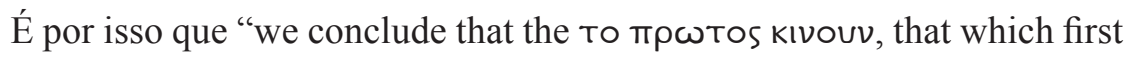
moveth in us, and is the spring and principle of all deliberative action, can be no other than a constant, restless, uninterrupted desire, or love of good as such, and happiness" "36. A felicidade não é o bem. A felicidade é o amor pelo bem.

Como já referi atrás, Cudworth, na linha de avaliação estóica da liberdade, reconhece que não somos completamente passivos e condenados ao reino da total necessidade: "We seem clearly to be led by the instincts of nature that 
there is something ef emin, in nostra potestate, in our own power (though dependently upon God Almighty)" ${ }^{37}$. Se não existisse esta margem de manobra, esta autonomia, estava o homem inibido, eu diria mesmo constitutivamente, para "praise and dispraise, commend and blame (men) for their actings" 38 .

Ora esta atitude moral é a prova de que não só possuímos a suficiente autonomia para tais juízos, mas também que possuímos faculdades para exercer esse poder, faculdades cognoscitivas e faculdades deliberativas. E para a questão da autonomia são tão importantes umas quanto as outras. A própria noção de imputabilidade e de responsabilidade moral decorre dum prévio sentido de autonomia já reconhecido: "we do not impute the evil of all men's wicked actions to God the creator and maker of them, after the same manner as we do the faults of a clock or watch wholly to the watchmaker"39.

Em resumo o homem não vive num reino de absoluta necessidade. Possui liberdade e autonomia. Não haveria vida moral, uma vez que não haveria responsabilidade, se não houvesse liberdade e autonomia, isto é, se não se verificasse aquilo que disse Cícero e que Cudworth sublinhou, isto é a culpabilidade imputada ao mal cometido, malum culpae.

É do reconhecimento da responsabilidade e da autonomia, volto a insistir, no reconhecimento de que há coisas que estão no nosso poder (a palavra poder é aqui carregada de uma forte conotação humanista), que decorre a construção por Cudworth do autexousious power. Em boa verdade este poder não é mais do que o eph' hemin (sui potestas) estóico. E é claro, porque os conceitos não valem só pelo que imediatamente significam mas também pelo que desencadeiam, quer dizer, pelas consequências intelectuais que promovem, que o reconhecimento da liberdade e da autonomia fomenta o sentido da perfectibilidade, da capacidade de transformar as coisas, de as melhorar, etc. Todo o universo ideológico que virá a triunfar com as Luzes; com os seus ideais próprios ligados aos conceitos em que a ideologia se cristaliza (perfectibilidade, progresso, optimismo, pedagogia, aprendizagem); se desdobra a partir da assunção de um valor humanista fundamental, o da autonomia, que confere ao agente um poder (liberdade) para transformar as coisas: “(...) there is a contingent liberty, and that men have something in their own power add something of their own, so that they can change themselves, and all things are not linked and tied in a fatal adamantine chain of causes" 40 . 
O inimigo que está no horizonte continua a ser o voluntarismo e o positivismo sobretudo pelo que neles se cristaliza de predestinação, fatalidade, pessimismo ontológico etc., e sendo assim, Cudworth regressa à teorização da liberdade paradoxalmente subtraindo alguma liberdade ao próprio Deus, o que era totalmente inaceitável por parte da linha teológica de orientação puritana. "(...) it may be well concluded that God can act nothing contrary to the same law of his own perfections, that is, can do nothing either foolishly or unjustly"41.

A promoção da autonomia do autexousious power comporta ainda uma consequência de natureza teológica de extrema importância pela sua relação eminente com a heresia pelagianista. É pela existência deste poder, e da liberdade que o comporta, e desta autonomia que o põe em marcha, que justamente os actos humanos são merecedores de encómio ou condenação. Ou seja, o poder permite julgar e o exercício desse poder de julgar colocanos na alçada de um julgamento sobre nós próprios. O poder da autonomia coloca directamente na soleira do processo de salvação, já que permite uma valorização moral dos actos. A autonomia é processualmente soteriológica. Como, de resto, já se sabia, o pelagianismo comportava como perigo maior justamente este perigo de que o homem se pudesse tornar um Deus para si mesmo. O pelagianismo comportava a autonomia e a autonomia desencadeia uma soteriologia de tipo pelagiano. Permita-se-me que circularmente regresse ao ponto de partida: quando o ser se dota, através de um poder de autonomia, do poder de se salvar, o ser está no caminho da sua própria divinização, ou seja, de se tornar um Deus para si próprio. É, e sempre foi, o pecado da hybris que incluiu este desvio humanista. E isto apesar de a tradição humanista poder comportar, como comporta, desde a cultura clássica, uma dimensão que se opõe ao excesso e se determina pela moderação, pela temperança e pela medida. Há na tradição humanista uma mediania ôntica associada a um excesso ontológico. É esta contradição que alimenta um conflito estrutural no seio da tradição religiosa, desde sempre. A tradição humanista incorpora em si simultaneamente o excesso dionisíaco de todos os prometeus e faustos da nossa cultura e ao mesmo tempo o "gentilhomme» e o pequeno burguês. Em síntese: o excesso e a media res.

\subsubsection{A autonomia em Ralph Cudworth. Análise complementar.}

Poderia dizer-se, sem especulação, que o mais importante do pensamento do Neoplatonismo de Cambridge se subsume nesta passagem da obra 
de Platão: "Then Knowledge does not consist in impressions of sense, but in reasoning about them; in that only, and not in the mere impression, truth and being can be attained"42.

Uma boa proposição é por vezes mais esclarecedora que amplos discursos sobre um tema. O que se diz aqui, extraído do Teeteto de Platão, mas citado a partir do texto de Cassirer, The Platonique Renaissance, é para mim de uma enorme utilidade para aprofundar a perspectiva da autonomia em Ralph Cudworth. Tenho a certeza que ele próprio, Cudworth, e mesmo todo o Neoplatonismo de Cambridge, no seu conjunto, assinariam por baixo, sem hesitações, este pequeno trecho. E, no entanto, Cassirer, que o usa, não tirou a meu ver todas as ilações possíveis, quer dizer, todas as potencialidades que o texto encerra. Esta reflexão de Platão podia ser de Cudworth e foi com essa intenção que Cassirer aqui a incluiu, de tal modo que logo a seguir confessa que esta citação dá o mote ao pensamento próprio de Cudworth e mesmo assim continuou a referir-se ao neoplatonismo como um movimento intelectual, essencialmente contemplativo e meramente teorético, em cuja epistemologia se desenha um retrocesso em direcção ao panteísmo da Renascença. Foi isso mesmo que ele disse. Mas agora nesta passagem do seu trabalho acrescenta e sobre Cudworth que "all knowledge is actio not reactio; it is free creation and association, not reception" 43 .

Eu não podia estar mais de acordo. Esta concepção de conhecimento, assim como o modo como implicitamente desvaloriza o conhecimento sensista, permite perceber imediatamente a íntima relação entre o empirismo, o sensismo e os sectores mais conservadores da Igreja e da sociedade, assim como a luta sem quartel que continuava, nesta época e ainda depois, a ser conduzida contra a razão. É o momento de introduzir aqui o que, muito acertadamente, Charles Taylor escreveu sobre o assunto: Reconhecendo que existe uma afinidade histórica entre o «empiricist mechanism» e o «Puritans theological voluntarism», e que inclusivamente este enlace foi já notado, referir-se-á talvez a Cassirer ou a Windelband, ou aos dois, acrescenta de seu moto e a meu ver num sentido totalmente correcto,

"this theological outlook itself pushed towards the adoption of the mechanistic world picture, (...) God's sovereignty was best safeguarded in face of a creation without purpose of its own. But the disengaged subject resembles the Deity in this respect. Disengagement, (...) operates by objectifying the domain in question, rendering it neutral. The disengaged subject of empiricist mechanism takes over some of the 
prerogatives accorded God in Occamist theology. Indeed, in some ways the new outlook can be seen as a kind of anthropological transposition of this theology"44.

Ora, era essa neutralidade que asfixiava o humanismo, uma vez que ela favorecia a assunção de uma lógica de poder e de domínio, como já se viu, tanto sobre as coisas como sobre o próprio homem. E, pelo contrário, era contra essa neutralidade anti-humanista que porfiava a teologia do Neoplatonismo de Cambridge. Este é que era o cerne da questão senão em consciência pelo menos o que subterraneamente alimentava a discórdia e, sem sombra de dúvida, o que acabou por vir à superfície e alimentou as explorações que tenho vindo a explorar (Cassirer, Taylor, Windelband, entre outras).

O voluntarismo do pensamento puritano presente em Hobbes e em Locke, por exemplo, chocava profundamente os Cambridge Platonists e muito em particular Cudworth, e o grande objectivo tornou-se a defesa da liberdade religiosa, assim como da sua beleza intelectual, contra as formas de fanatismo e de irracionalidade. Só que a mobilização retórica e argumentativa contra o voluntarismo positivista, contra a sua arbitrariedade legal, por um lado, e contra a sua desvalorização do homem e da inteligência, por outro, forçou a construção de um modelo parapelagiano e profundamente humanista.

Foi talvez no plano jurídico que melhor se exprimiu a rebelião de Cudworth contra a heteronomia e o domínio cego, a que já aludi.

Nesse plano, a perspectiva de Ralph Cudworth é muito estimulante do ponto de vista em que coloco a minha análise. Ele diz, e cito Cassirer, que

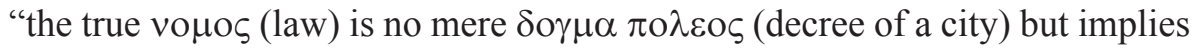
something substantial, self-existing, and valid in its own right, it is tou ovtos

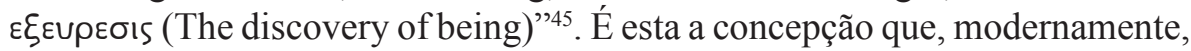
foi adquirindo a autonomia para o sujeito moderno. O homem dá-se a lei para si mesmo e submete-se-lhe.

$\mathrm{Na}$ articulação de Cudworth explora-se ainda o elemento mais orgânico e não o elemento puramente artificial. E se é verdade que esta identificação da norma com a descoberta do ser pretenda conferir à norma uma essencialidade ontológica, que ela perderá mesmo em Kant, não é menos verdade que se pode ler a locução como sendo a expressão de uma procura universal da norma, aquela norma que seja capaz de se impor tanto ao indivíduo quanto à comunidade.

44 Taylor, C., Sources of the self: The making of modern identity, Cambridge: Cambridge University Press, 1989, pp. 248 e 249.

45 Cassirer, E., The platonic renaissance in England, Nova lorque: Gordian Press, 1970, p. 80. 
Mais adiante, Cassirer toca o âmago da questão quando diz que "in its controversy with Calvinistic dogma the Cambridge School now occupies exactly the same position that Pelagius had taken against Augustine, and Erasmus against Luther" ${ }^{\prime 6}$. Já o tinha percebido e desde sempre me pareceu que a grande fronteira do conflito, mas não apenas deste conflito regional, mas de toda a conflitualidade que eclode a partir da protomodernidade, é a do humanismo contra os seus inimigos. Ora, para este efeito, nada é mais indicado que trazer Pelágio a terreiro. De facto ele é e será sempre a melhor metáfora do humanismo.

E para deixar Cassirer em paz, por agora, nada melhor que persegui-lo até às últimas frases deste seu capítulo III, porque irá dizer o que já esperava e nada mais do que isto, no fim de contas, que o Neoplatonismo de Cambridge preparou a superação do conflito a que acabei de fazer referência na medida em que preparou a autonomia do imperativo categórico kantiano. Para Cassirer, tal como para Alain Renaut por exemplo, também Leibniz desempenhará um papel relevante neste trajecto: "They form two independent movements tending toward the same end; they are two important stages on the way of leading from Luther to Kant, from the concept of freedom of freedom of idealism, from the principle of justification by faith to the principle of the autonomy of the will and of practical reason"47.

Confesso que foi com muita satisfação que anotei esta última proposição e nela, muito em particular, uma palavra, «autonomy», e uma expressão, «practical reason».

Só não compreendo, mas provavelmente não irei compreender, porque provavelmente não serão compreensíveis, os motivos pelos quais Cassirer não extrai as consequências que a sua análise implica, nas linhas essenciais. A verdade é que conhecendo eu o teor fundamental da sua grande obra $A$ filosofia das luzes e sabendo que nela uma das ideias mais inovadoras para a época, mas para mim a mais perniciosa, estava na definição das Luzes como sendo um movimento intelectual que resultou do cruzamento da racionalidade à francesa, e portanto sempre com a marca do cartesianismo, com o empirismo inglês, não posso deixar de compreender apenas que the fosse de todo impossível explorar as vicissitudes perversas e anti-iluministas desse mesmo empirismo inglês. Provavelmente. Mas porquê? É como se o autor que escreveu $A$ filosofia das luzes não fosse o mesmo que escreveu $O$ renascimento platónico em Inglaterra. 